\title{
Bcl-2 Protein as a Marker of Neuronal Immaturity in Postnatal Primate Brain
}

\author{
Patrick J. Bernier and André Parent \\ Laboratoire de Neurobiologie, Centre de recherche Université Laval Robert-Giffard, Beauport, Québec, Canada G1J 2G3
}

The distribution of neurons expressing immunoreactivity for the protein Bcl-2 was studied in the brain of squirrel monkeys (Saimiri sciureus) of various ages. Several subsets of small and intensely immunoreactive neurons displaying an immature appearance were disclosed in the amygdala and piriform cortex. The piriform cortex exhibited clusters of various forms in which $\mathrm{Bcl}-2+$ neurons appeared linked to one another by their own neurites. The subventricular zone, which is known to harbor the largest population of rapidly and constitutively proliferating cells in the adult rat brain, was intensely stained, particularly at the basis of the lateral ventricle. A long and dorsoventrally oriented $\mathrm{Bcl}-2+$ fiber fascicle was seen to emerge from the subventricular zone, together with numerous Bcl-2+ cells that formed a densely packed column directed at the olfactory tubercle. In adult and aged monkeys, the small and intensely labeled neurons were progressively replaced by larger and more weakly stained neurons in the amygdala and piriform cortex. In contrast, Bcl-2 immunostaining did not change with age in the subventricular zone and olfactory tubercle, the islands of Calleja of which were markedly enriched with Bcl-2. The dentate gyrus contained only a few layers of intensely labeled granule cells in juvenile monkeys, but the number of these layers increased markedly in adult and aged monkeys. These findings suggest that $\mathrm{Bcl}-2$ can serve as a marker of both proliferating and differentiating neurons and indicate that such immature neurons may be much more widespread than previously thought in postnatal primate brain.

Key words: Bcl-2 protein; bcl-2 proto-oncogene; brain maturation; neuron differentiation; aging; subventricular zone; adult brain neurogenesis; progenitors cells
The $b c l-2$ proto-oncogene was first detected at the breakpoint of the $\mathrm{t}(14 ; 18)$ chromosomal translocation that occurs in human follicular lymphoma (Tsujimoto et al., 1985). Juxtaposition of the $b c l-2$ gene to the enhancer of the immunoglobulin gene heavy chain results in a high expression of Bcl-2 transcripts (Cleary and Sklar, 1985). Although Bcl-2 protein is not in itself oncogenic, it is suggested to contribute to neoplasia by acting as a repressor of apoptosis, which is a physiological process in which a cell actively kills itself after an extracellular or intracellular signal (programmed cell death). Transfected neurons that overexpressed Bcl-2 in culture are protected against apoptosis induced by diverse types of stress (Garcia et al., 1992; Behl et al., 1993; Zhong et al., 1993). Transgenic mice that overexpress Bcl-2 have a larger number of neurons in their postnatal brain compared with wildtype mice of the same strain (Martinou et al., 1994). Neurons in these transgenic mice are particularly resistant to axotomy (Dubois-Dauphin et al., 1994; Farlie et al., 1995; Bonfati et al., 1996) and ischemia (Martinou et al., 1994). In contrast, mice with a targeted disruption of the $b c l-2$ gene display a marked decrease in the volume of the neocortex, cerebellum, and several other brains structures, as well as a significant reduction of the axonal diameter in both the peripheral nervous system (PNS) and CNS (Henderson et al., 1995). In addition to its antiapoptosis function,

\footnotetext{
Received Sept. 29, 1997; revised Jan. 8, 1998; accepted Jan. 15, 1998.

This work was supported by Grant MT5781 from the Medical Research Council of Canada to A.P. P.J.B. was holding a Studentship from the National Science and Engineering Research Council of Canada. We express sincere gratitude to $\mathbf{M}$. Didier and C. Brechenmacher for their help in transfection studies and to R. D. McKay for the generous gift of nestin antibodies.

Correspondence should be addressed to Dr. André Parent, Laboratoire de Neurobiologie, Centre de Recherche Université Laval Robert-Giffard, 2601 de la Canardière, Local F-6500, Beauport, Québec, Canada G1J 2 G3.

Copyright (C) 1998 Society for Neuroscience $0270-6474 / 98 / 182486-12 \$ 05.00 / 0$
}

Bcl-2 protein has been shown to promote regeneration of severed axons in the CNS (Chen et al., 1997) and to be involved in the regulation of neuronal differentiation (Sato et al., 1994; Z hang et al., 1996).

The overall distribution of Bcl-2 protein and mRNA has been investigated in the rat (Castrén et al., 1994; Merry et al., 1994), and some information is also available regarding the occurrence of Bcl-2 in certain structures of the human brain (Hara et al., 1996; Vyas et al., 1997). Bcl-2 was found to be more widely distributed in the developing than in the adult rodent brain, except for some regions in which postnatal neurogenesis and differentiation occur (e.g., dentate gyrus and olfactory bulb). In contrast, neurons of the PNS were found to continuously express a high level of bcl-2 from embryonic stages to adulthood.

The present study provides evidence for the presence of Bcl-2 in areas of the brain of the squirrel monkey that are actively involved in neurogenesis and morphogenesis. We also report the existence of variations in the expression of this protein that occur during aging. Our data suggest that $\mathrm{Bcl}-2$ may play a role in neurogenesis and/or neural differentiation in several structures of the postnatal primate brain.

\section{MATERIALS AND METHODS}

Preparation of tissue. The present data derive from the analysis of sections taken from the brains of 12 male squirrel monkeys (Saimiri sciureus). These monkeys were born in captivity, and four of them were juveniles (10-23 months old), seven were young to middle-age adults (4.2-5.9 yr old), and one was an aged animal (10 yr old). All monkeys were deeply anesthetized with sodium pentobarbital and perfused transcardially with cold $\left(4^{\circ} \mathrm{C}\right) 0.9 \%$ saline solution prepared with PBS, $0.1 \mathrm{M}, \mathrm{pH} 7.4$, and containing heparin $(1 \mathrm{ml} / \mathrm{l})$, followed by a cold solution of fixative $(4 \%$ paraformaldehyde plus $0.1 \%$ glutaraldehyde in phosphate buffer, $0.1 \mathrm{M}$, $\mathrm{pH}$ 7.4). Brains were removed, post-fixed overnight at $4^{\circ} \mathrm{C}$ in the latter fixative, and placed into graded solutions of sucrose (10-30\% in PBS) 
before being cut on a freezing microtome into $40-\mu \mathrm{m}$-thick coronal sections. The sections were serially collected and kept frozen in a cryoprotecting solution before being processed for immunohistochemistry. The animals were treated according to the guidelines of the Canadian Council on Animal Care, and our experimental protocol was approved by Laval University Committee on Ethics and Animal Research.

Immunohistochemistry. The presence of $\mathrm{Bcl}-2$ protein was revealed by using a mouse monoclonal antibody (mAb) (clone 124; Boehringer Mannheim, Mannheim, Germany), which was raised against human Bcl-2 protein (Pezzella et al., 1990). Complete series of sections taken from the forebrain and upper brainstem of each animal were incubated during 48 $\mathrm{hr}$ at $4^{\circ} \mathrm{C}$ in a solution containing the anti-Bcl-2 antibody (dilution, 1:50), $0.08 \%$ Triton X-100 (Sigma, St. Louis, MO), and 5\% normal horse serum (NHS) in PBS (0.1 M, pH 7.4). They were then incubated for $1 \mathrm{hr}$ at room temperature in $0.4 \%$ biotinylated anti-mouse $\mathrm{IgG}$ (Vector Laboratories, Burlingame, CA). After washing in PBS, the sections were reincubated for $1 \mathrm{hr}$ at room temperature in 2\% avidin-biotin complex (ABC Elite, Vector Laboratories), according to the method of Hsu et al. (1981), and Bcl-2 immunoprecipitate was revealed with nickel-intensified 3,3'diaminobenzidine (Sigma) as the chromogen. Control sections incubated without the anti-Bcl-2 antibody remained virtually free of immunostaining. All sections were dehydrated, mounted onto dry gelatin-coated slides with Permount, and analyzed with a Leitz microscope. Series of section adjacent to those immunoreacted with Bcl-2 antibody were stained with cresyl violet to help in the identification of the various brains structures.

Immunofluorescence. Some sections taken through the rostral portion of the striatum in an adult monkey were treated with a doubleimmunofluorescence procedure to reveal the possible colocalization of Bcl-2 and the protein nestin in cells of the subependymal zone. The sections were incubated for $24 \mathrm{hr}$ at $4^{\circ} \mathrm{C}$ in a solution containing nestin antibody (1:600), Triton X-100 (0.08\%, Sigma), and 5\% NHS in PBS (0.1 $\mathrm{M}, \mathrm{pH}$ 7.4). They were then incubated for $1 \mathrm{hr}$ at room temperature in $0.4 \%$ biotinylated anti-rabbit IgG (Vector Laboratories), washed in PBS, and placed for $3 \mathrm{hr}$ at room temperature in streptavidin conjugated to Texas Red (dilution, 1:160; Molecular Probes, Eugene, OR). The primary antibody used here (a generous gift from Dr. Ron D. McKay, National Institute of Neurological Diseases and Stroke, National Institutes of Health, Bethesda, MD) was raised in rabbit against recombinant rat nestin expressed in Escherichia coli (Tohyama et al., 1992). This polyclonal antibody was shown to recognized nestin in a highly specific manner and in a wide variety of species, including rat, mouse, and human. After extensive washing in PBS, the same sections were reincubated for $48 \mathrm{hr}$ at $4^{\circ} \mathrm{C}$ in a solution containing the anti-Bcl-2 antibody (dilution, 1:50), $0.08 \%$ Triton X-100 (Sigma), and 5\% NHS in PBS (0.1 $\mathrm{M}, \mathrm{pH}$ 7.4). They were then incubated for $1 \mathrm{hr}$ at room temperature in $0.4 \%$ biotinylated anti-mouse $\operatorname{IgG}$ (Vector Laboratories), washed in PBS, and placed for $3 \mathrm{hr}$ at room temperature in streptavidin conjugated to fluorescein isothiocyanate (FITC) (dilution, 1:260; BioCan, Mississauga, Ontario, Canada). After extensive washing, the sections were mounted with DPX and observed under a Zeiss microscope equipped with an epifluorescence illumination system.

Western blotting. Another adult squirrel monkey was deeply anesthetized with sodium pentobarbital and perfused transcardially with cold $\left(4^{\circ} \mathrm{C}\right) 0.9 \%$ saline solution in PBS $(0.1 \mathrm{M}, \mathrm{pH} 7.4)$. After thorough washing of the brain, one hemisphere was rapidly dissected out and served for the immunoblot experiments. The rest of the brain was perfused with fixative solutions (as described above) and served for anatomical and immunohistochemical studies. The unfixed hemisphere was placed on an ice-cold plate, and samples from several structures, including the amygdala and hippocampal formation, were taken out and immediately frozen in liquid nitrogen. Protein extraction was initiated by placing tissue samples in $120 \mu \mathrm{l}$ of extraction buffer $(0.25 \mathrm{M}$ Tris, $\mathrm{pH} 7.8$, $10 \mathrm{~mm}$ EDTA, and $2 \mu \mathrm{g} / \mathrm{ml}$ aprotinin). The samples were then vortexed until major tissue pieces were disrupted and kept on ice for $20 \mathrm{~min}$. Extracts were sonicated and then centrifuged at $4^{\circ} \mathrm{C}$ for $10 \mathrm{~min}$ at $8000 \times$ $g$. Supernatants were collected, and the protein concentration was determined with the BCA protein assay (Bio-Rad, Hercules, CA). Samples including $20,25,30$, and $35 \mu \mathrm{g}$ of protein were fractionated by SDSPAGE (12\% polyacrylamide) and then electroblotted to Immobilon-P membranes (Millipore, Bedford, MA). The protein blots were then blocked $45 \mathrm{~min}$ in $5 \%$ nonfat milk and incubated overnight at $4^{\circ} \mathrm{C}$ in a PBS solution containing anti-human Bcl-2 mAb (clone 124; dilution, $1: 100), 0.1 \%$ Triton $\mathrm{X}-100$, and $1 \%$ nonfat dry milk. The Bcl-2 antibody was detected by using HRP-conjugated donkey anti-mouse antibody

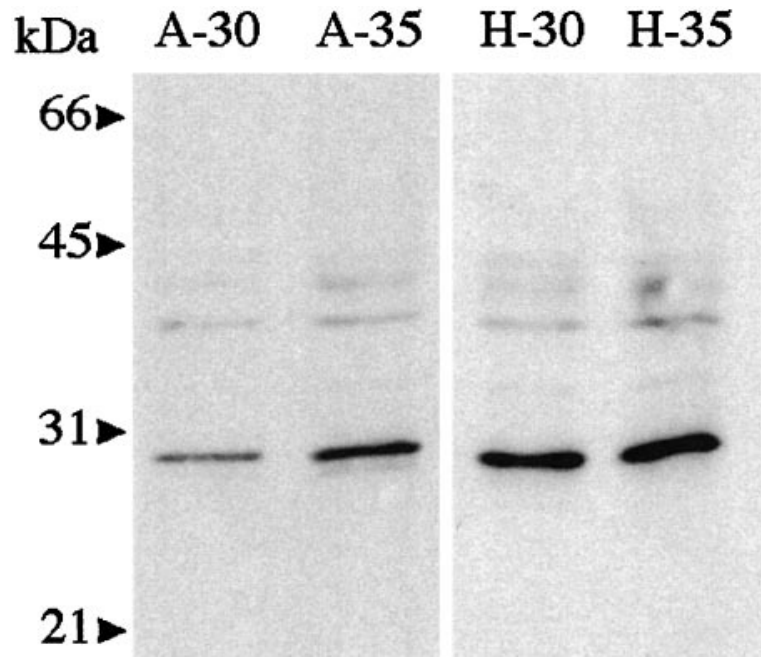

Figure 1. Western blot analysis of monkey brain extracts for Bcl-2 protein. Thirty and $35 \mu \mathrm{g}$ of amygdala $(A-30$ and $A-35)$ and hippocampus ( $H$-30 and $H-35)$ protein extracts were loaded on SDS-PAGE gels. Anti$\mathrm{Bcl}-2$ antibody (clone 124) recognizes a single major band of $\sim 26 \mathrm{kDa}$ in both samples.

(Jackson ImmunoResearch, West Grove, PA) and the chemiluminescence method (DuPont NEN, Boston, MA).

Expression of human Bcl-2 and Bcl-XL cDNA in vero cells. Vero (African green monkey embryonic kidney) cells were transfected according to the procedure of Graham and Van der Eb (1973), with pRC/ cytomegalovirus (CMV) expression vector containing human $\mathrm{Bcl}-2$ or human Bcl-XL encoding cDNA (a gift from Dr. C. B. Thompson, University of Chicago, Chicago, IL). The cells were then fixed with $4 \%$ paraformaldehyde during $10 \mathrm{~min}$. The expression of $\mathrm{Bcl}-2$ protein was revealed with a mAb raised against human $\mathrm{Bcl}-2$ (clone 124), and that of $\mathrm{Bcl}-\mathrm{XL}$ protein was revealed with a polyclonal antibody raised against human Bcl-X (Transduction Laboratories, Lexington, KY). Both antibodies were diluted $1: 50$ in a PBS solution containing $0,05 \%$ Triton $\mathrm{X}-100$ and $5 \%$ NHS. The staining of primary antibodies was obtained by incubation with biotinylated, affinity-purified donkey anti-mouse IgG for Bcl-2 and biotinylated donkey anti-rabbit IgG for Bcl-X antibody (dilution, 1:500, Jackson ImmunoResearch), followed by incubation with streptavidin conjugated to FITC (dilution, 1:500; Jackson ImmunoResearch).

\section{RESULTS}

\section{Specificity of the anti-Bcl-2 (clone 124) mAb}

The mAb (clone 124) used in the present study was raised against a synthetic peptide corresponding to amino acids 41-54 of the human Bcl-2 protein (Pezzella et al., 1990). Western blot studies made on protein samples from different human tissues, including the brain, have shown that clone 124 antibody recognized the characteristic $26 \mathrm{kDa}$ band corresponding to $\mathrm{Bcl}-2$ protein (Pezzella et al., 1990; Ben-Ezra et al., 1994; Vyas et al., 1997).

Our own Western blot analysis has demonstrated the high affinity of clone 124 antibody for Bcl-2 protein in the squirrel monkey brain. Clone 124 antibody recognized a single major band migrating at $\sim 26 \mathrm{kDa}$, which is consistent with the molecular weight of Bcl-2 protein (Pezzella et al., 1990; Hockenbery et al., 1991; Haldar et al., 1994) (Fig. 1). Interestingly, the band recognized by the Bcl-2 antibody was larger for hippocampus than amygdala for the same amount of protein extract. Thus, there appears to be more Bcl-2 protein expressed in the hippocampal region than in amygdala of the squirrel monkey, a finding that is congruent with immunohistochemical data (see below).

The specificity of the anti-Bcl-2 antibody was further assessed by transfection studies on vero cells that overexpressed either 
Bcl-2 or Bcl-XL protein. The anti-Bcl-2 antibody was found to specifically stain vero cells that overexpressed $\mathrm{Bcl}-2$ protein, leaving the untransfected cells, as well as cells that overexpressed Bcl-XL, totally free of immunostaining (Fig. 2). The Bcl-XLoverexpressing cells were intensely stained by the anti-Bcl-X antibody (data not shown). These results confirm the specificity of clone 124 anti-Bcl-2 antibody for Bcl-2 protein in monkey (vero) cells and reveal its lack of cross-reactivity with the Bcl-2homologous protein Bcl-XL.

\section{Bcl-2 immunostaining}

A particularly prominent immunoreactivity for Bcl-2 protein was noted in several structures or regions of the squirrel monkey brain, including the amygdala, piriform cortex, hippocampus, olfactory tubercle, subventricular zone, insula, and the ventrolateral portion of temporal and frontal cortices (Fig. 3; see Figs. 5, 8). Two types of Bcl-2+ neurons could be defined on the basis of morphological criteria and immunostaining peculiarities: (1) type A neurons with small, round, or oval perikarya displaying intense and uniform Bcl-2 immunoreactivity and emitting long immunostained processes; and (2) type B neurons with larger pleomorphic perikarya exhibiting a moderate and granular Bcl-2 immunoreactivity but lacking immunostained processes, except for some proximal (primary) dendrites that were occasionally stained (see Fig. $8 C-E$ ). These two types of $\mathrm{Bcl}-2+$ neurons were distributed according to similar patterns in each of the four juveniles and in each of seven adult monkeys, but some conspicuous variations in the expression of Bcl-2 were noted between juvenile, adult, and aged animals.

\section{Amygdala and piriform cortex}

A large number of type A neurons were encountered within the ventral portion of the amygdala in juvenile monkeys (Fig. $3 A$ ). The distribution of these neurons did not obey the cytoarchitectural subdivision of the amygdala. The Bcl-2+ neurons abounded particularly within the paralaminar nucleus, which lies along the myelinated fiber fascicle that separates the amygdala from the surrounding cortex, but also occurred along the external border of the lateral amygdaloid nucleus and within the ventral aspect of the basal amygdaloid nucleus. The pattern of organization of these neurons was particularly remarkable in juvenile monkeys, in which many of them formed a thick and intensely immunostained layer composed of densely packed type A neurons aligned along the white matter. The processes of these neurons were also oriented horizontally within the plane of the layer. Many other type A Bcl-2+ neurons were seen to detach themselves from this layer and to invade deeper regions of the amygdala, in which they formed clusters of various sizes and shapes. These neurons characteristically displayed intensely stained processes oriented in all directions. Some of these processes remained attached to the main layer of immunoreactive cells, whereas others were linked to immunoreactive neurons lying close to the strongly Bcl-2+ layer (Fig. 4A-C). More deeply in the amygdala, many of these Bcl-2+ processes were intertwined with one another, thus forming an impressive array of thick fascicles that ran dorsally to join the ventral amygdalof ugal pathway (Fig. 3A,B).

The type A neurons were progressively replaced by larger and more deeply located type B neurons in the amygdala of adult and aged monkeys (Fig. 3). These type B neurons were much more numerous and more intensely stained in the aged animal than in the adults. They were also more widely and more deeply distributed in the amygdala than the type A neurons. A significant
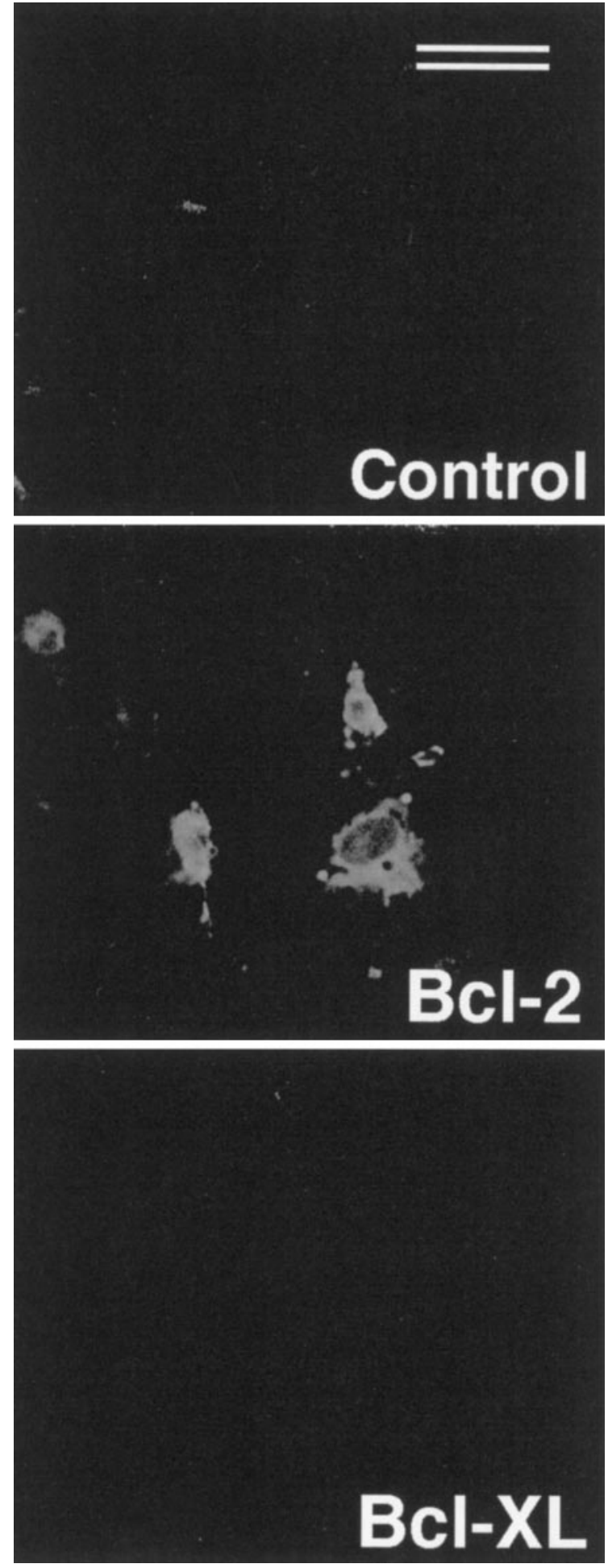

Figure 2. Confirmation of the specificity of the anti-human Bcl-2 antibody (clone 124) for $\mathrm{Bcl}-2$ protein by transfection studies in monkey (vero) cells. A specific Bcl-2 immunofluorescence was detected only in vero cells transfected by a $\mathrm{pRC} / \mathrm{CMV}$ expression vector containing the human Bcl-2 cDNA sequence (middle). No immunostaining was observed in untransfected cells (top) or in cells transfected by a pRC/CMV expression vector containing the human Bcl-XL cDNA sequence (bottom). Scale bar, $50 \mu \mathrm{m}$. 

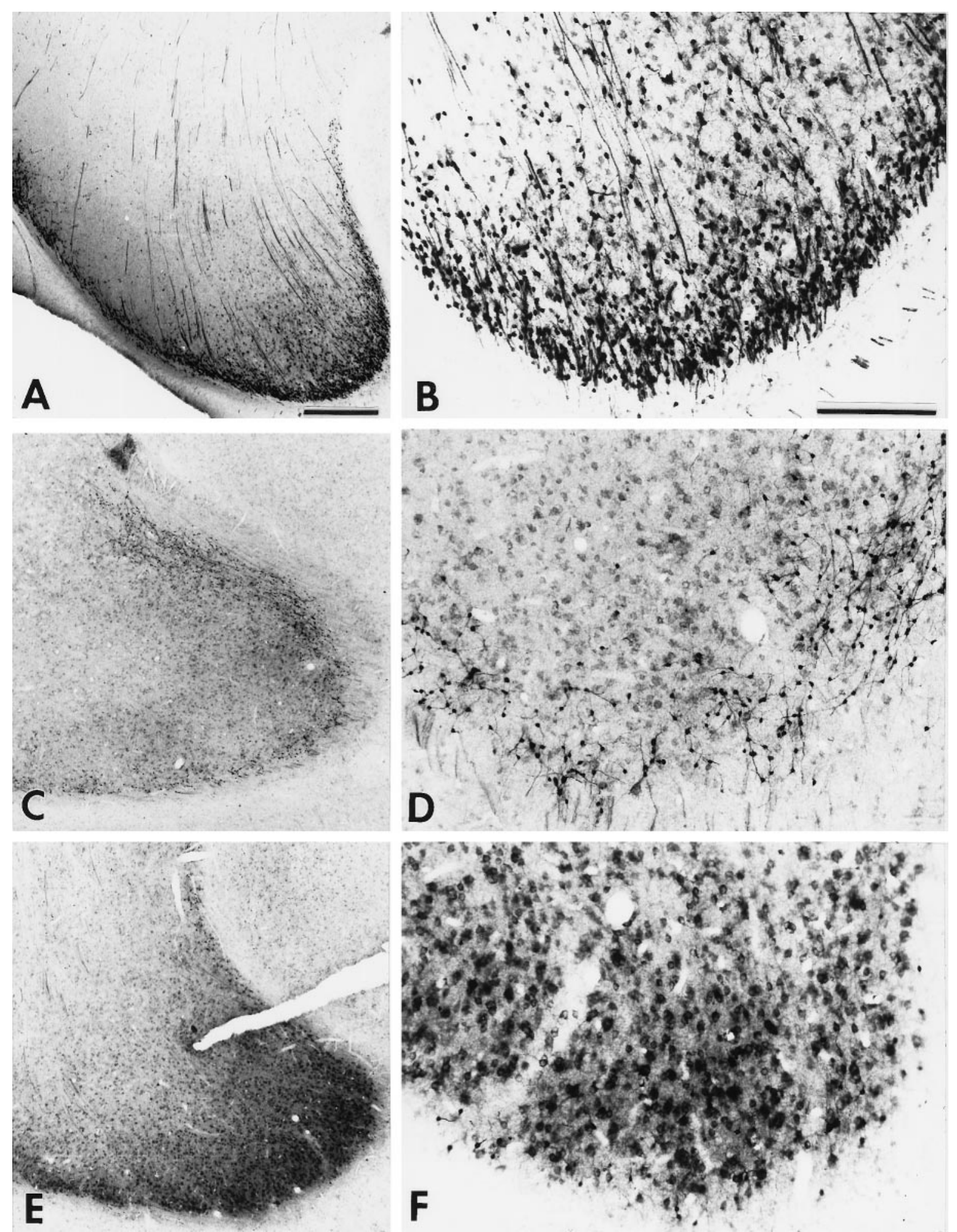

Figure 3. Variations in the pattern of Bcl-2 immunostaining of the amygdala among juvenile, adult, and aged squirrel monkeys. Frontal sections are from midamygdaloid levels in the three cases, and the material is shown at both low $(A, C, E)$ and higher $(B, D, F)$ magnifications. $A, B$, In juvenile monkeys, the immunostaining is particularly prominent in the basomedial sector of the amygdala, and many labeled fiber fascicles emerge from the positive cells and ascend dorsally within the amygdala $(A)$. This immunostaining is the result of the accumulation of numerous intensely stained small and round neurons $(B)$. $C, D$, In adult animals, Bcl-2 immunostaining is decreased by comparison with juveniles $(C)$, as a result of a loss in the number of small, intensely immunoreactive neurons. However, note the presence of some larger and more weakly immunostained neurons located more deeply in the amygdala $(D) . E, F$, In the aged monkey, Bcl-2 immunostaining is relatively intense $(E)$. This is largely caused by a marked increase in the number of large and moderately stained neurons, with only a few small and intensely immunoreactive neurons remaining along the lateral border of the amygdala $(F)$. Scale bars: $A, C, E, 500 \mu \mathrm{m} ; B, D, F, 200 \mu \mathrm{m}$. 

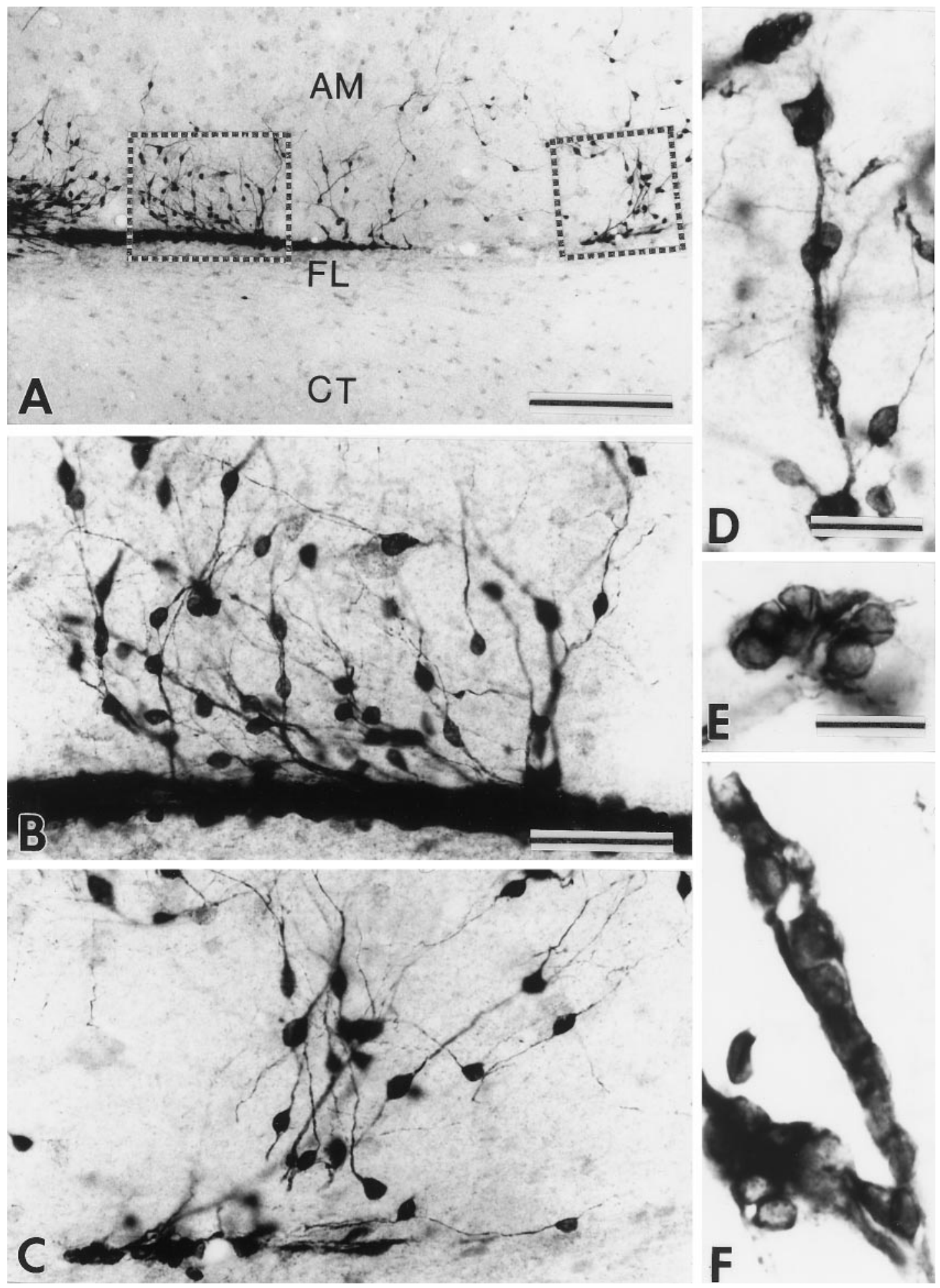

Figure 4. Examples of the immature features displayed by Bcl-2-positive neurons in amygdala $(A-C)$ and piriform cortex $(D-F)$ of juvenile monkeys. $A$, Low-power view of the intensely immunostained neurons lying at the basis of the amygdala $(A M)$, along the fiber layer $(F L)$ that separates the amygdala from the adjoining entorhinal cortex $(C T) . B, C$, High-power view of two clusters of immunoreactive neurons, the exact location of which in the amygdala is indicated by insets in $A$. $D$, A small collection of Bcl-2-positive neurons linked together by their long and linear processes in the piriform cortex. $E$, A small round group of closely packed immunoreactive neurons displaying a peculiar arrangement in the piriform cortex. $F$, Elongated immunoreactive structure in the piriform cortex composed of closely packed Bcl-2-positive cells embedded in a tubular sheath that appears to be formed by the cells own processes. Scale bars: $A, 200 \mu \mathrm{m} ; B, C, 50 \mu \mathrm{m} ; D, 25 \mu \mathrm{m} ; E, F, 15 \mu \mathrm{m}$. 
number of type A neurons persisted in the amygdaloid complex of adult monkeys, but only a few of them could be visualized in the aged animal (Fig. 3). The intensely stained processes that formed ascending fascicles were still present, albeit in significantly lesser number, in the amygdaloid complex of adult and aged monkeys (Fig. 3).

The piriform cortex also displayed a striking immunostaining pattern in juvenile monkeys. The Bcl-2 labeling at this level consisted of numerous densely packed clusters of type A cells, which seemed linked to one another by their own neurites (Fig. $4 D$ ). In some cases, Bcl-2+ cells were so closely apposed to one another that they appeared as peculiar aggregates of various forms, including that of an elongated tube within which the cell bodies were embedded (Fig. 4E,F). Additionally, several long and rectilinear $\mathrm{Bcl}-2+$ processes were seen to emerge from these neurons and to invade the amygdaloid complex dorsally. Type A $\mathrm{Bcl}-2+$ neurons in the piriform cortex of juvenile monkeys were progressively replaced by type $B$ neurons in adult and aged monkeys, but this change was more subtle in the piriform cortex than it was in the amygdala.

\section{Hippocampal formation}

In juvenile monkeys, a particularly intense Bcl-2 immunostaining was observed at the level of the dentate gyrus (Fig. 5). The labeling was largely confined to the closely packed neurons of the granule cell layer, which all displayed a type A Bcl-2 immunostaining. This staining was somewhat atypical, however, because these Bcl-2+ neurons were devoid of well stained processes. The molecular layer of the dentate gyrus also exhibited moderately intense Bcl-2 immunostaining, but this labeling was largely confined to the neuropil. The polymorph layer, in contrast, was totally devoid of Bcl-2+ elements (Fig. 5A,B). The hippocampus proper (CA fields), as well as the subicular cortex, were also poorly labeled for Bcl-2.

In contrast to what was seen at the amygdala level, a remarkable increase in type A Bcl-2 immunostaining was observed in the hippocampal formation of adult and aged monkeys (Fig. $5 C, D$ ) by comparison with juvenile animals (Fig. $5 A, B$ ). This was the result of a significant augmentation in the number of type $\mathrm{A} \mathrm{Bcl}-2+$ neurons within the granule cell layer of the dentate gyrus. These Bcl-2+ neurons formed a thin (two- to three-cell-thick) layer located at the border between the granule and polymorph layers in juvenile monkeys (Fig. $5 E$ ). In adult and aged monkeys, however, Bcl-2+ neurons stand out as a prominent 10- to 12-cell-thick layer after what appears to have been a proliferation of granule cells in an inside-out manner, that is, from the polymorph to the molecular layer (Fig. $5 F$ ). Despite their increase in number, Bcl-2 + neurons of dentate gyrus were not more intensely stained in adult and aged monkeys than in juveniles.

\section{Olfactory tubercle, subventricular zone, and glial septum}

The olfactory tubercle located beneath the rostral part of the striatum contained a multitude of Bcl-2+ neurons. These neurons were largely confined to the granular layer of the olfactory tubercle and formed the so-called islands of Calleja. Virtually all islands of Calleja, including the major island that borders the nucleus accumbens, were enriched with Bcl-2 (Fig. 6A). At rostral levels, these darkly stained islands appeared more or less continuous with one another, and many of them encroached on the plexiform layer and extended down as far as the pial surface (Fig. $6 A$ ). Each island contained a multitude of small granule $\mathrm{Bcl}-2+$ cells that displayed a type A immunostaining pattern (Fig. 6B).
A prominent Bcl-2 immunoreactivity occurred within the socalled subventricular zone (SVZ) along most of the lateral and third ventricles in the squirrel monkey. This type of immunostaining was particularly obvious at the ventral tip of the frontal horn of the lateral ventricle, in which numerous intensely stained cells without clearly visible processes were seen just beneath the ependymal wall (Fig. 6C,D). These cells formed a closely packed column directed toward the ventral surface of the brain. Furthermore, long Bcl-2+ fiber fascicles emerged from the ependymal layer at the SVZ level and ran ventrally along the medial border of the nucleus accumbens (Fig. 6C). These labeled fibers could be followed as far down as the olfactory tubercle. Doubleimmunofluorescence studies showed that a large proportion of Bcl-2+ cells in the SVZ also expressed nestin, the major intermediate filament (IF) protein that is commonly used as a specific marker of embryonic CNS progenitor cells (Fig. 7).

The glial septum consists of a series of glial cells that are aligned along the midline and separate the brainstem into two halves. It is involved in the guidance of axonal growth during development and is believed to disappear during maturation. Immunostaining for $\mathrm{Bcl}-2$, however, clearly revealed the persistence of this structure in juvenile, adult, and even aged monkeys (Fig. 6E).

\section{Neocortex}

At cortical levels, Bcl-2 immunoreactivity occurred principally in neurons located throughout the insula and in the ventrolateral portions of the temporal and frontal cortices in juvenile monkeys. In insular, temporal, and frontal cortices, Bcl-2+ neurons were largely confined to the supragranular layers, particularly layer II, and most of them exhibited type A immunostaining (Fig. 8C,D). In the ventral part of the temporal cortex, Bcl-2+ neurons of type $\mathrm{B}$ were also visualized in infragranular layers, particularly the lower part of layer V and upper part of layer VI. The small type A Bcl-2+ neurons that populated layer II in juveniles were no longer visible in the adult and aged monkeys (Fig. 8A,B). However, type $B$ neurons that occurred in infragranular layers persisted in adult and old animals (Fig. 8B). These type B neurons had a typical pyramidal-shaped perikarya with a long apical process that ascended toward more superficial layers of the temporal cortex (Fig. 8E). The Bcl-2 immunostaining visualized in the other cortical areas (i.e., dorsolateral part of temporal cortex, ventral part of frontal cortex, and insular cortex) in juvenile monkeys was no longer present in adult and aged monkeys (Fig. $8 F-H)$.

\section{DISCUSSION}

\section{Variation of $\mathrm{Bcl}-2$ immunostaining patterns with aging}

The expression of Bcl-2 is known to change markedly during late postnatal maturation and aging of the brain (Castrén et al., 1994; Merry et al., 1994; Kroemer, 1997; Merry and Korsmeyer, 1997; Reed, 1997). In the squirrel monkey, two types of changes have been noted: a progressive loss of immunostaining and a switch from type A to type B immunostaining. Losses of Bcl-2 immunostaining occur in the cerebral cortex, whereas the amygdala and piriform cortex are two structures in which small intensely stained Bcl-2+ cells (type A neurons) are progressively replaced by larger and more weakly stained cells (type B neurons) during the course of aging. A very intense Bcl-2 immunostaining of small neurons has been observed during prenatal development of the rat brain, particularly in the cortical plate in which postmitotic neurons begin to send out processes and form synaptic connec- 

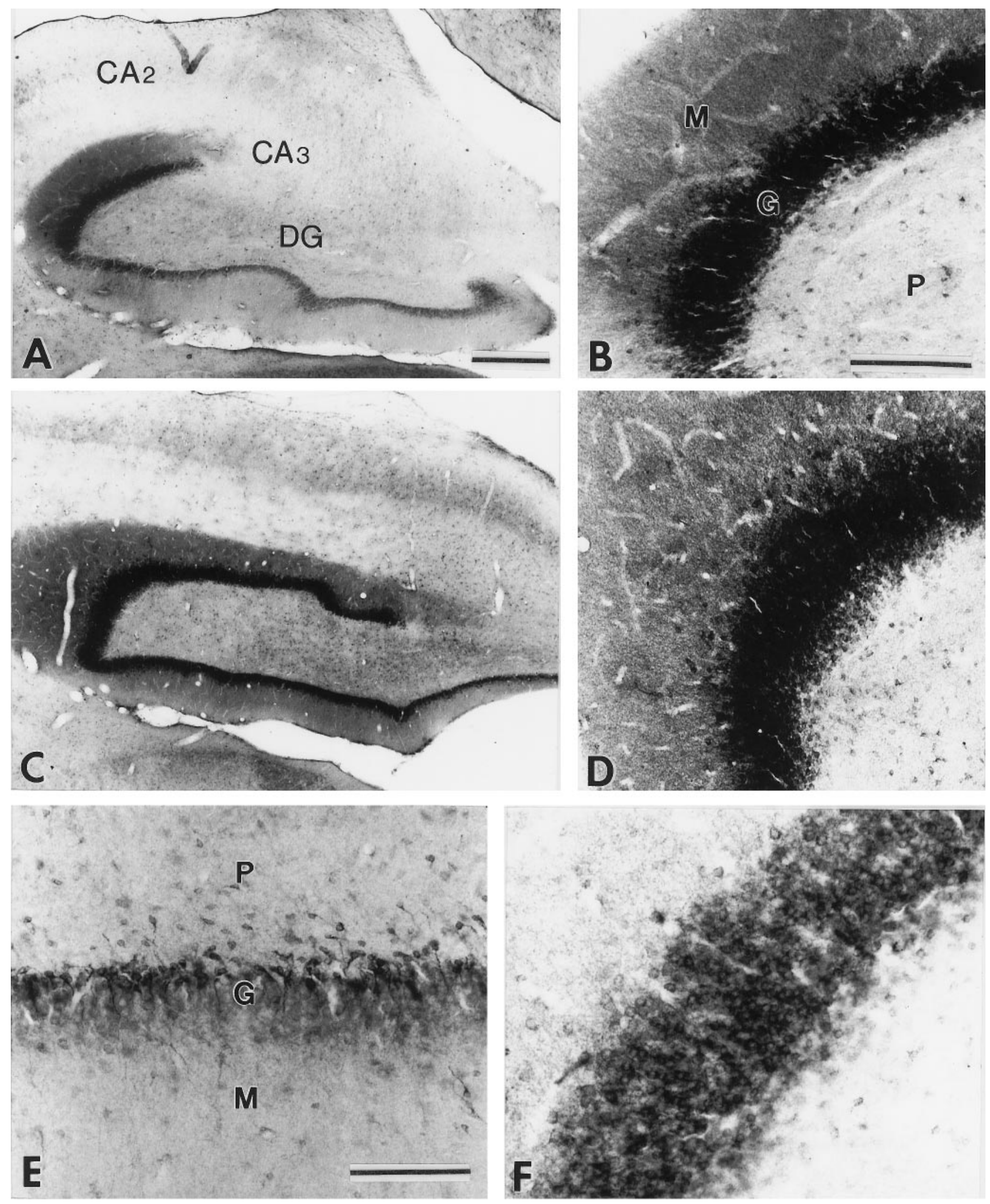

Figure 5. Variations in patterns of Bcl-2 immunostaining in the hippocampus of juvenile $(A, B, E)$ and adult squirrel monkeys $(C, D, F)$. At this level, Bcl-2 immunoreactivity is largely confined to perikarya of granule cell layer and neuropil of the molecular layer, leaving the polymorph layer relatively free of immunostaining. $A, B$, In juvenile monkeys, the granule cell layer is thin, and the neuropil of the molecular layer is moderately stained. $C$, $D$, In adult monkeys, the granular layer is thicker, and the immunostaining in certain sectors of the molecular layer is more intense than in juveniles. $E$, $F$, High-power views of similarly intense immunoreactive neurons in the granular layer in juveniles $(E)$ and in adult $(F)$ monkeys. $C A 2, C A 3$, Fields 2 and 3, respectively, of Ammon's horn (cornu ammonis); $D G$, dentate gyrus with its molecular $(M)$, granular $(G)$, and polymorph $(P)$ layers. Scale bars: $A$, $C, 500 \mu \mathrm{m} ; B, D, 200 \mu \mathrm{m} ; E, F, 100 \mu \mathrm{m}$. 

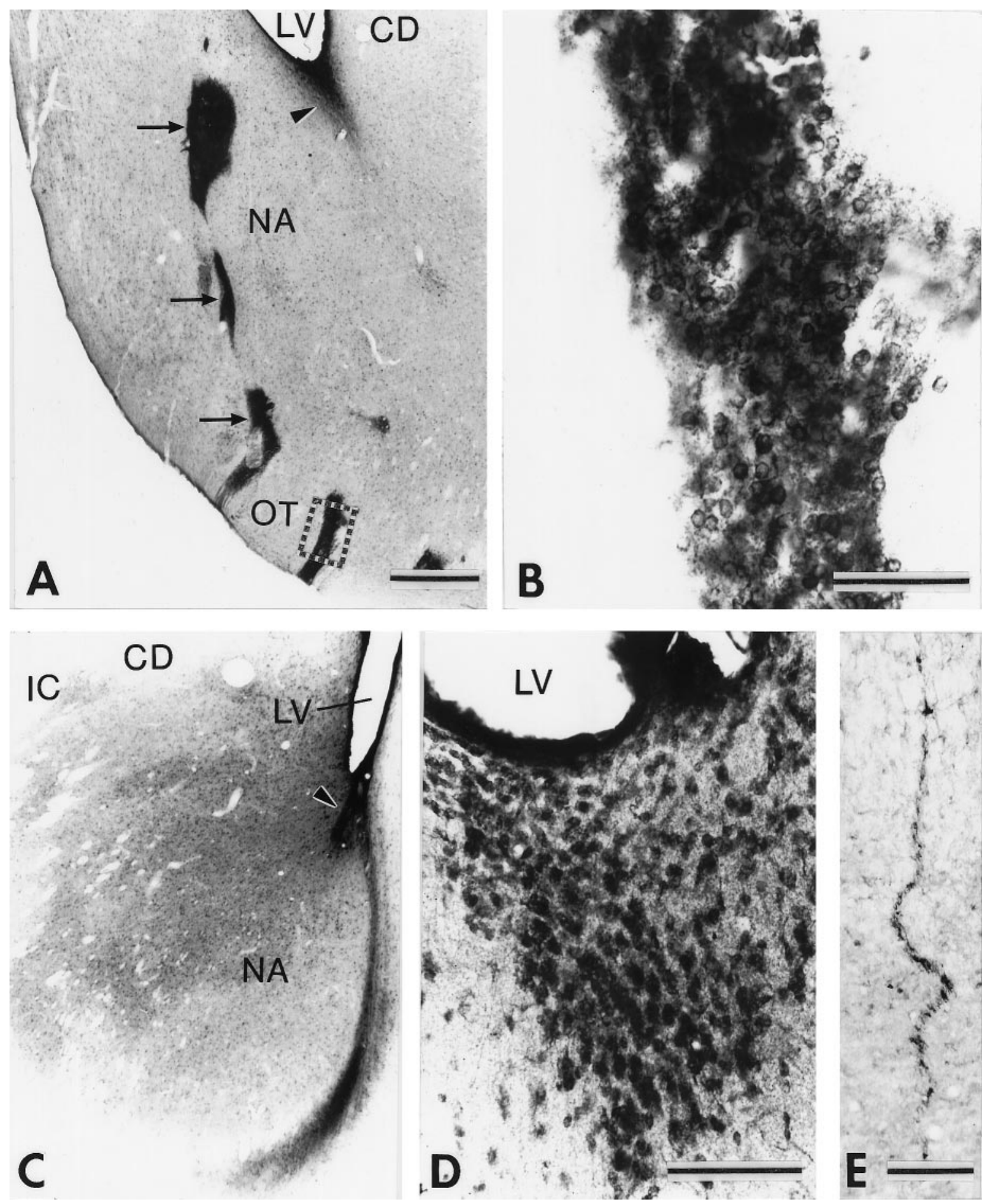

Figure 6. A, Intense Bcl-2 immunoreactivity encountered in the islands of Calleja (arrows), which are scattered within the olfactory tubercle (OT), and in the subventricular zone (arrowhead) at the basis of the lateral ventricle $(L V)$. B. High-power view of the multitude of small and intensely stained neurons encountered in one of the island of Calleja (inset in $A$ ). $C$, A fascicle formed by numerous Bcl-2-immunostained fibers that stem from the ventral tip of the lateral ventricle and course along the medial border of nucleus accumbens $(N A)$. The location of the caudate nucleus $(C D)$ and internal capsule $(I C)$ is also indicated. $D$, High-power view of Bcl-2-positive cells in the subventricular zone located at the ventral tip of the lateral ventricle (arrowhead in $C$ ). $E$, The Bcl-2-positive glial septum located along the midline in the lower brainstem. Photomicrographs were taken from sections of different juvenile monkey brains. Scale bars: $A, C, 500 \mu \mathrm{m} ; B, 50 \mu \mathrm{m} ; D, 100 \mu \mathrm{m} ; E, 125 \mu \mathrm{m}$.

tions (Merry et al., 1994). This type of Bcl-2 labeling appears very similar to the type A immunostaining observed in the present study. Such a staining could thus be indicative of immature, postmitotic neurons that have not completed their differentiation or, at least, have not yet fully established their connections. These neurons may need Bcl-2 for axonal outgrowth and synapse formation. In contrast, postnatal maturation of neurons is accompanied by a decrease in Bcl-2 expression, which leads to a weaker 

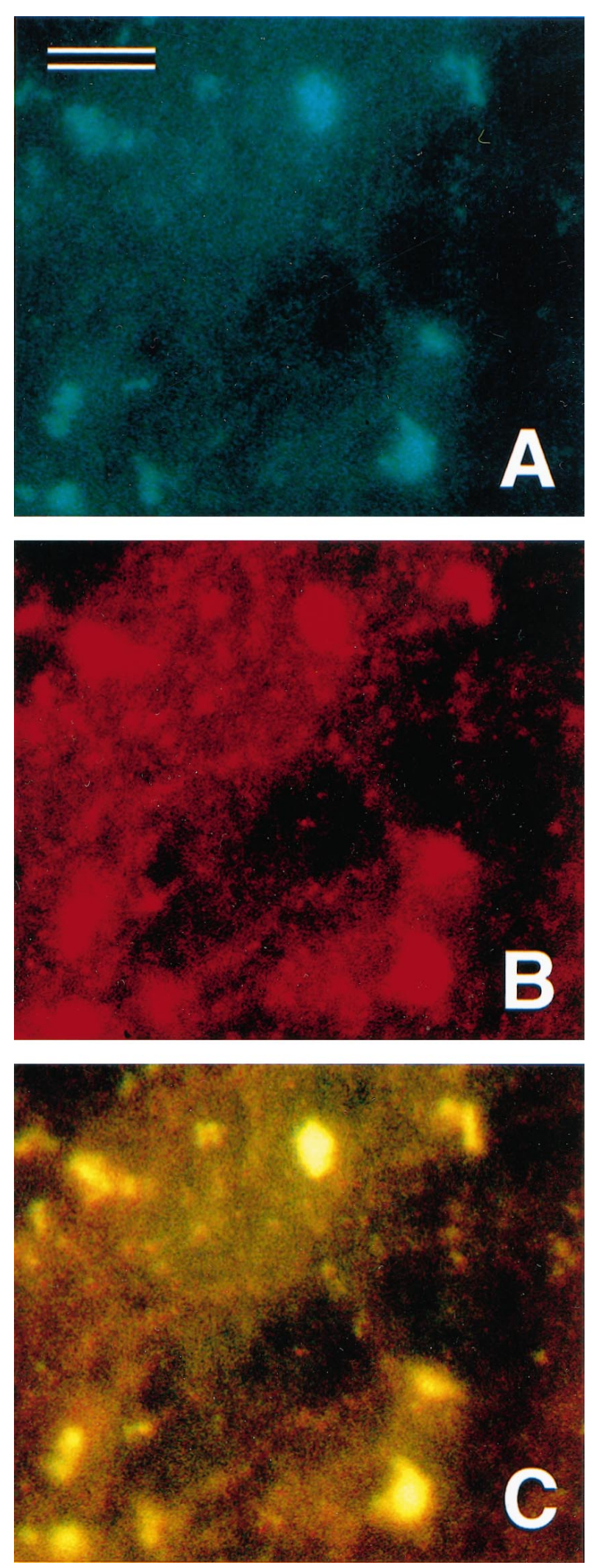

Figure 7. Cells in the SVZ of an adult monkey expressing both Bcl-2 and nestin, as visualized on the same section with a doubleimmunofluorescence procedure. The doubly labeled cells display a green FITC fluorescence indicative of $\operatorname{Bcl}-2(A)$, as well as a Texas Red fluorescence indicative of nestin $(B)$. The photomicrograph in $C$ is a double exposure of the same group of cells, the yellow color of which confirms the colocalization of Bcl-2 and nestin. Scale bar, $30 \mu \mathrm{m}$. and more granular Bcl-2 immunoreactivity (Merry et al., 1994), similar to the type B immunostaining observed in the present study. This type of immunostaining could correspond to more mature and more fully differentiated neurons. If we accept the idea that the type A cells, which abound in the amygdala and piriform cortex of juvenile primates, represent immature neurons, their progressive replacement by type B neurons during maturation and aging could simply reflect the transformation of these amygdaloid cells from the immature state to that of postmitotic long-lived neurons.

The dentate gyrus is one of the rare brain regions in rodents in which mitotically active neuroblasts occur throughout life (Kaplan and Hinds, 1977; Bayer et al., 1982). As in the rat (Castrén et al., 1994; Merry et al., 1994), the granule cells of the dentate gyrus in the squirrel monkey display an intense Bcl-2 immunostaining. At variance with other brain structures, however, there appears to be an increase in the number of Bcl-2+ cells at the level of the granular layer of the dentate gyrus in adult and aged monkeys compared with juvenile animals. These results suggest that Bcl-2 is expressed in proliferating neuroblasts, in differentiating and maturing postmitotic neurons, and in mature long-lived postmitotic neurons in the primate dentate gyrus. These findings are at odds with those obtained with $\left[{ }^{3} \mathrm{H}\right]$ thymidine autoradiography $\left(\left[{ }^{3} \mathrm{H}\right] \mathrm{TdR}\right)$, which indicate that neurogenesis ceases after puberty in the dentate gyrus of the rhesus monkey (Eckenhoff and Rakic, 1988).

\section{$\mathrm{Bcl}-2$ in neuronal proliferation and differentiation}

The bcl-2 proto-oncogene is widely expressed during CNS development (Merry et al., 1994). Neurons that fail to reach their proper target during development are likely to die by apoptosis because of a lack of sufficient target-derived neurotrophic factors (Davies, 1995). By acting as an antidote to apoptosis, Bcl-2 can rescue such neurons and, by doing so, can play a major role in the shaping of neural structures and in the establishment of neural circuitry (Buchman and Davies, 1993; Korsmeyer, 1993; Williams and Smith, 1993). Furthermore, recent evidence suggests that neurons on their way to their final location can avoid apoptosis by upregulating Bcl-2 via autocrine stimulation (Muller et al., 1997). Experimental studies show that prolonged neuronal survival is observed when an increase in the expression of $b c l-2$ is achieved through gene transfer methods, whereas antisense-mediated reduction of $b c l-2$ gene expression leads to a marked increase in neuronal death in a setting of neurotrophic factor withdrawal (LeBrun et al., 1993; Martinou et al., 1994; Reed, 1994; Allsopp et al., 1995; Henderson et al., 1995).

Recent evidence suggests that Bcl-2 may also be involved in the regulation of neural differentiation (Hanada et al., 1993; Sato et al., 1994). An in vitro study using a human neural crest-derived tumor cell line has shown that overexpression of $b c l-2$ cDNA induces extensive neurite outgrowth, together with an increased expression of neuron-specific enolase (Zhang et al., 1996). In contrast, cells expressing an antisense bcl-2 cDNA construct, which reduces the endogenous levels of $\mathrm{Bcl}-2$, do not undergo spontaneous neural differentiation and acquire an epithelial morphology, even in the presence of an adequate quantity of the appropriate neurotrophic factor.

Altogether, these findings suggest that the presence of high levels of Bcl-2 expression (type A immunostaining) could be indicative of both proliferating neurons and postmitotic neurons that are not yet fully differentiated. Hence, the numerous Bcl-2+ neurons displaying a very peculiar morphological organization in 

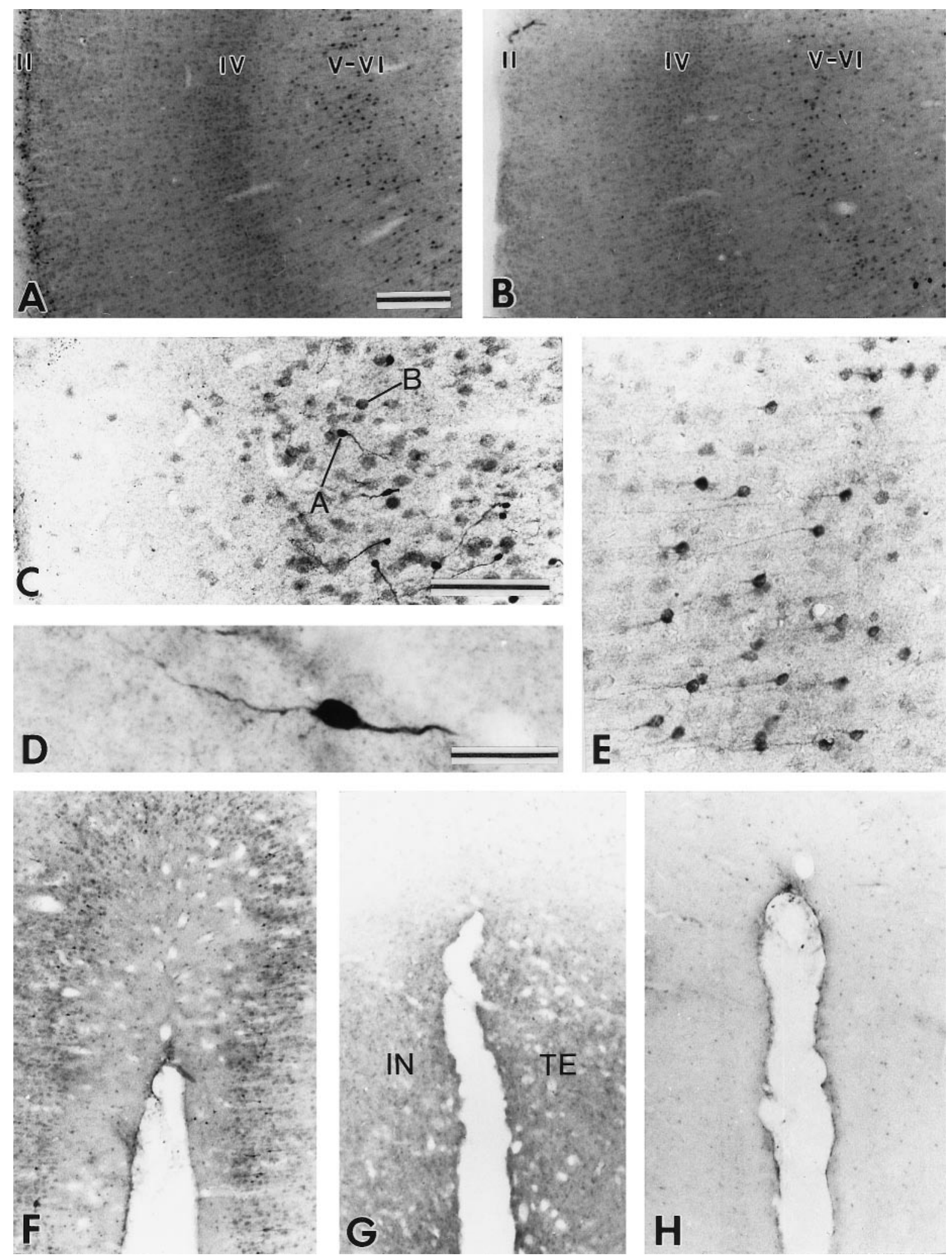

Figure 8. Variations of the pattern of Bcl-2 immunostaining in the cortex of juvenile, adult, and aged squirrel monkeys. $A, B$, In the temporal cortex of juveniles $(A), \mathrm{Bcl}-2$-positive neurons are confined to supragranular layers, particularly layer $I I$, and in infragranular layers, particularly layer $V$ and, to a lesser extent, layer $V I$, whereas in the adults and aged animals $(B)$ the immunoreactive neurons are concentrated in infragranular layers. $C$, Layer II in juvenile monkeys contains both type A and type B Bcl-2-immunopositive neurons. $D$, Type A neurons are intensely stained with clearly visible processes. $E$, Layers V-VI in adult and aged monkeys are populated by small pyramidal neurons with well delineated apical dendrites. $F-H$, The moderate Bcl-2 immunostaining observed in the supragranular layers of the insular $(I N)$ and temporal $(T E)$ cortices of juveniles monkeys $(F)$ becomes very weak in adult monkeys $(G)$ and virtually absent in the aged monkey $(H)$. Scale bars: $A, B, F, G, H, 250 \mu \mathrm{m} ; C, E, 100 \mu \mathrm{m} ; D, 20 \mu \mathrm{m}$. 
the amygdala and piriform cortex of the squirrel monkey could be immature neurons. The fact that type A neurons are progressively replaced by type B neurons in these structures in adult and aged monkeys suggests that neuronal maturation in these two brain regions prolongs itself well into adulthood.

\section{$\mathrm{Bcl}-2$ in the subventricular zone and olfactory structures}

In the rat, the SVZ harbors the largest population of rapidly and constitutively proliferating cells in the adult brain (Morshead et al., 1994; Weiss et al., 1996). Adult progenitor cells generated in the SVZ bordering the most rostral region of the lateral ventricle differentiated into new neurons that migrate along a pathway defined by neural cell adhesion molecules (NCAMs) (the socalled rostral migratory stream) to the olfactory bulb in which they become granule cells and periglomerular neurons (Altman and Das, 1966; Luskin, 1993; Lois and Alvarez-Buylla, 1994). Although $\left[{ }^{3} \mathrm{H}\right] \mathrm{TdR}$ studies have indicated that neurogenesis does not extend beyond early postnatal life in primates (Rakic, 1985), a recent bromodeoxyuridine-labeling experiment in adult rhesus monkeys has revealed the existence of neural precursor cells in SVZ that respond to growth factors and can generate both neurons and glial cells (Leonard et al., 1997). The presence of numerous Bcl-2+ cells in the SVZ lining the rostral tip of the lateral ventricle in squirrel monkeys strongly supports the idea that actively proliferating subventricular cells exist in primates. The fact that a large number of Bcl-2+ cells in the SVZ in the squirrel monkey also express nestin, the major IF protein of the embryonic CNS progenitor cells (Tohyama et al., 1992), strengthens even further such a view.

The protein Bcl-2 is expressed by cells present in the germinal zones of the embryonic rat brain (Hockenbery et al., 1991; LeBrun et al., 1993; Castrén et al., 1994; Merry et al., 1994). It is likely to be expressed by both progenitor cells that are destined to remain in the SVZ and cells that will migrate and differentiate into the granule and periglomerular cells of the olfactory bulb and may serve to protect these cells from apoptosis. Interestingly, the presence of abundant Bcl-2-immunoreactive granule cells in the islands of Calleja in the squirrel monkey suggests that the subventricular cells that migrate along the NCAM-defined pathway to the olfactory bulb may also populate the olfactory tubercle. Also of interest is the presence of intensely labeled Bcl-2+ neurons in the monkey amygdala and surrounding piriform cortex, two areas known to be closely linked to the olfactory system. Our data reveal that the basal or rhinencephalic part of the limbic system in primates is composed of a Bcl-2-rich cellular continuum, the principal relay stations of which are the olfactory bulb, the olfactory tubercle, the basolateral amygdala, and the piriform cortex. The intense Bcl-2+ fiber fascicles that were seen leaving the amygdala and piriform cortex may serve to convey information integrated within this cellular continuum to other structures of the basal forebrain, particularly the hypothalamus.

\section{Conclusions}

The present data together with the results of previous investigations have yielded important clues about the possible role of Bcl-2 in the CNS. Among the most important findings are the following: (1) intense Bcl-2 immunoreactivity (similar to type A neurons) occurs principally in zones of neural differentiation, maturation, and, to a lesser extent, in neural proliferation in the embryonic brain (Merry et al., 1994); (2) Bcl-2 continues to be expressed throughout adulthood in the PNS, in which neurons can resume their capacity to differentiate (Hockenbery et al., 1991; Merry et al., 1994); (3) brain areas in which neurogenesis occurs throughout life (e.g., olfactory bulb, dentate gyrus, and SVZ) are markedly enriched with Bcl-2 (Castrén et al., 1994; Merry et al., 1994) (present study); (4) Bcl-2 and nestin are coexpressed in SVZ neurons (present study); (5) the glial septum, a neural migrating guide, persists and retains its Bcl-2 immunoreactivity throughout adulthood; likewise, the thick fiber fascicles that emerge from the SVZ are highly stained for Bcl-2 (present study); (6) the density of neurons displaying type A Bcl-2 immunoreactivity strikingly decreases during brain maturation and aging (present study); (7) $\mathrm{Bcl}-2$ is directly involved in neural differentiation, and its overexpression enables neurons in adult CNS to regenerate their axons (Sato et al., 1994; Chen et al., 1997); and (8) intensely stained Bcl-2+ neurons (type A) in amygdala and piriform cortex possess an immature-like morphology and organization (present study).

In light of these findings, we propose that neurons displaying high levels of Bcl-2 immunostaining as well as an immature-like appearance, which occur in specific areas of the primate brain, are indeed neurons that have not yet completed their maturation. The presence of such neurons in the amygdala and piriform cortex suggests that areas in which neurogenesis and morphogenesis occur throughout life may be more widespread than previously believed in the primate brain.

\section{REFERENCES}

Allsopp TE, Kiselev S, Wyatt S, Davies AM (1995) Role of Bcl-2 in the brain-derived neurotrophic factor survival response. Eur J Neurosci 7:1266-1272.

Altman J, Das GD (1966) Autoradiographic and histological studies of postnatal neurogenesis. I. A longitudinal investigation of the kinetics, migration and transformation of cells incorporating tritiated thymidine in neonate rats, with special reference to postnatal neurogenesis is some brain regions. J Comp Neurol 126:337-389.

Bayer SA, Yakel JW, Puri PS (1982) Neurons in the rat dentate gyrus granular layer substantially increase during juvenile and adult life. Science 216:890-892.

Behl C, Hovey III L, Krajewski S, Schubert D, Reed JC (1993) Bcl-2 prevents killing of neuronal cells by glutamate but not by amyloid beta protein. Biochem Biophys Res Commun 197:949-956.

Ben-Ezra JM, Kornstein MJ, Grimes MM, Krystal G (1994) Small cell carcinoma of the lung express the Bcl-2 protein. Am J Pathol 145:1036-1040.

Bonfati L, Strettori E, Chierzi S, Cenni MC, Liu XH, Martinou JC, Maffei L, Rabacchi SA (1996) Protection of retinal ganglion cells from natural and axotomy-induced cell death in neonatal transgenic mice overexpressing bcl-2. J Neurosci 16:4186-4194.

Buchman VL, Davies AM (1993) Different neurotrophins are expressed and act in a developmental sequence to promote the survival of embryonic sensory neurons. Development 118:989-1001.

Castrén E, Ohga Y, Berzaghi MP, Tzimagiorgis G, Thonen H, Lindholm D (1994) bcl-2 messenger RNA is localized in neurons of the developing and adult rat brain. Neuroscience 61:165-177.

Chen DF, Schneider GE, Martinou JC, Tonegawa S (1997) Bcl-2 promotes regeneration of severed axons in mammalian CNS. Nature 385:434-439.

Cleary ML, Sklar J (1985) Nucleotide sequence of a t(14;18) chromosomal breakpoint cluster region near a transcriptionally active locus on chromosome 18. Proc Natl Acad Sci USA 82:7439-7443.

Davies AM (1995) The Bcl-2 family of proteins, and the regulation of neuronal survival. Trends Neurosci 18:355-358.

Dubois-Dauphin M, Frankowski H, Tsujimoto Y, Huarte J, Martinou JC (1994) Neonatal motoneurons overexpressing the bcl-2 protooncogene in transgenic mice are protected from axotomy-induced cell death. Proc Natl Acad Sci USA 91:3309-3313.

Eckenhoff M, Rakic P (1988) Nature and fate of proliferative cells in the hippocampal dentate gyrus during the life span of the rhesus monkey. J Neurosci 8:2729-2747. 
Farlie PG, Drigen R, Rees SM, Kannourakis G, Bernard O (1995) bcl-2 transgene expression can protect neurons against developmental and induced cell death. Proc Natl Acad Sci USA 92:4397-4401.

Garcia I, Martinou I, Tsujimoto Y, Martinou JC (1992) Prevention of programmed cell death of sympathetic neurons by the $b c l-2$ protooncogene. Science 258:302-304.

Graham JC, Van der Eb AJ (1973) A new technique for the assay of infectivity of human adenovirus 5 DNA. Virology 52:456-467.

Haldar S, Jena N, DuBois GC, Takayama S, Reed JC, Fu SF, Croce CM (1994) Purification and characterization of the bcl-2 protein. Arch Biochem Biophys 315:483-488.

Hanada M, Krajewski S, Tanaka S, Cazals-Hatem D, Spengler BA, Ross RA, Biedler JL, Reed JC (1993) Regulation of bcl-2 oncoprotein levels with differentiation of human neuroblastoma cells. Cancer Res 53:4978-4986.

Hara A, Hirose Y, Wang A, Yoshimi N, Tanaka T, Mori H (1996) Localization of Bax and Bcl-2 proteins, regulators of programmed cell death, in the human central nervous system. Virchows Arch A Pathol Anat Histopathol 429:249-253.

Henderson JT, Morshead CM, van der Kooy D, Loh DY, Roder JC (1995) Neurologic effects of $b c l-2$ gene ablation in mice. Soc Neurosci Abstr 21:1067.

Hockenbery DM, Zutter M, Hickey W, Nahm M, Korsmeyer SJ (1991) $\mathrm{Bcl}-2$ protein is topographically restricted in tissues characterized by apoptotic cell death. Proc Natl Acad Sci USA 88:6961-6965.

Hsu SM, Raine L, Fanger H (1981) Use of avidin-biotin-peroxidase complex $(\mathrm{ABC})$ in immunoperoxidase techniques: a comparison between $\mathrm{ABC}$ and unlabeled antibody (PAP) procedures. J Histochem Cytochem 21:557-580.

Kaplan MS, Hinds JW (1977) Neurogenesis in the adult rat: electron microscopic analysis of light radioautographs. Science 197:1092-1094.

Korsmeyer SJ (1993) Programmed cell death: Bcl-2. In: Important advances in oncology (DeVita VT, Helman S, Rosenberg SA, eds), pp 19-28. Philadelphia: Lippincott.

Kroemer G (1997) The proto-oncogene Bcl-2 and its role in regulating apoptosis. Nat Med 3:614-620.

LeBrun DP, Warnke RA, Cleary ML (1993) Expression of $b c l-2$ in fetal tissues suggests a role in morphogenesis. Am J Pathol 142:743-753.

Leonard CA, Olson M, Reynolds BA, Poulin P (1997) Central nervous system stem cells in the adult primate. Soc Neurosci Abstr 23:593.

Lois C, Alvarez-Buylla A (1994) Long-distance neuronal migration in the adult mammalian brain. Science 264:1145-1148.

Luskin MB (1993) Restricted proliferation and migration of postnatally generated neurons derived from the forebrain subventricular zone. Neuron 11:173-189.

Martinou JC, Dubois-Dauphin M, Staple JK, Rodriguez I, Frankowski H, Missotten M, Albertinin P, Talabot D, Catsicas S, Pietra C, Huarte J
(1994) Overexpression of Bcl-2 in transgenic mice protects neurons from naturally occurring cell death and experimental ischemia. Neuron 13:1017-1030.

Merry DE, Korsmeyer SJ (1997) bcl-2 gene family in the nervous system. Annu Rev Neurosci 20:245-267.

Merry DE, Veis DJ, Hickey WF, and Korsmeyer SJ (1994) Bcl-2 protein expression is widespread in the developing nervous system and retained in the adult PNS. Development 120:301-311.

Morshead CM, Reynold BA, Craig CG, McBurney MW, Staines WA, Morassutti D, Weiss S, van der Kooy D (1994) Neural stem cells in the adult mammalian forebrain: a relatively quiescent subpopulation of subependymal cells. Neuron 13:1071-1082.

Muller Y, Tangre K, Clos J (1997) Autocrine regulation of apoptosis and bcl-2 expression by nerve growth factor in early differentiating cerebellar granule neurons involves low affinity neurotrophin receptor. Neurochem Int 31:177-191.

Pezzella F, Tse AGD, Cordell JL, Pulford KAF, Gatter KC, Mason DY (1990) Expression of the bcl-2 oncogene protein is not specific for the 14;18 chromosomal translocation. Am J Pathol 137:225-232.

Rakic P (1985) Limits of neurogenesis in primates. Science 227: $1054-1046$.

Reed JC (1994) Bcl-2 and the regulation of programmed cell death. J Cell Biol 124:1-6.

Reed JC (1997) Double identity for proteins of the Bcl-2 family. Nature 387:773-776.

Sato N, Hotta K, Waguri S, Nitatori T, Tohyama K, Tsujimoto Y, Uchiyama Y (1994) Neuronal differentiation of PC12 cells as a result of prevention of cell death by bcl-2. J Neurobiol 25:1227-1234.

Tohyama T, Lee VM, Rorke LB, Marvin M, McKay RD, Trojanovski JQ (1992) Nestin expression in embryonic human neuroepithelium and in human neuroepithelial tumor cells. Lab Invest 66:303-313.

Tsujimoto Y, Gorham J, Cossman J, Jaffe E, Croce CM (1985) The $\mathrm{t}(14: 18)$ chromosome translocations involved in B-cell neoplasms result from mistake in VDJ joining. Science 229:1390-1393.

Vyas S, Javoy-Agid F, Herrero MT, Strada O, Boissiere F, Hibner U, Agid $\mathrm{Y}$ (1997) Expression of Bcl-2 in adult human brain regions with special reference to neurodegenerative disorders. J Neurochem 69:223-231.

Weiss S, Reynold BA, Vescovi AL, Morshead C, Craig CG, van der Kooy D (1996) Is there a neural stem cell in the mammalian forebrain? Trends Neurosci 19:387-393.

Williams GT, Smith CA (1993) Molecular regulation of apoptosis: genetic controls on cell death. Cell 74:777-779.

Zhang KZ, Westberg JA, Höltä E, Anderson LC (1996) Bcl-2 regulates neural differentiation. Proc Natl Acad Sci USA 93:4504-4508.

Zhong LT, Sarafian T, Kane DJ, Charles AC, Mah SP, Edwards RH, Bredesen DE (1993) bcl-2 inhibits death of central neural cells induced by multiple agents. Proc Natl Acad Sci USA 90:4533-4537. 